\title{
BMJ Open Prognostic factors for recovery of health status after injury: a prospective multicentre cohort study
}

\author{
Leonie de Munter (D) , ${ }^{1}$ Suzanne Polinder, ${ }^{2}$ Roos J M Havermans, ${ }^{3}$ \\ Ewout W Steyerberg, ${ }^{2,4}$ Mariska A C de Jongh ${ }^{1,3}$
}

To cite: de Munter L, Polinder S, Havermans RJM, et al. Prognostic factors for recovery of health status after injury: a prospective multicentre cohort study. BMJ Open 2021;11:e038707. doi:10.1136/ bmjopen-2020-038707

- Prepublication history and additional material for this paper are available online. To view these files, please visit the journal online (http://dx.doi. org/10.1136/bmjopen-2020038707).

Received 20 March 2020 Revised 11 November 2020 Accepted 29 November 2020

Check for updates

C Author(s) (or their employer(s)) 2021. Re-use permitted under CC BY-NC. No commercial re-use. See rights and permissions. Published by BMJ.

${ }^{1}$ Trauma TopCare, ElisabethTweeSteden Hospital, Tilburg, The Netherlands

${ }^{2}$ Public Health, Erasmus

Medical Center, Rotterdam, The Netherlands

${ }^{3}$ Brabant Trauma Registry, Network Emergency Care Brabant, Tilburg, The Netherlands

${ }^{4}$ Biomedical Data Sciences, Leiden University Medical Center, Leiden, The Netherlands

Correspondence to

Dr Leonie de Munter;

I.demunter@etz.nl

\section{ABSTRACT}

Objectives To determine prognostic factors for health status and recovery patterns during the first 2 years after injury in the clinical trauma population.

Design A prospective longitudinal cohort study.

Setting Ten participating hospitals in Brabant, the Netherlands.

Participants Injured adult patients admitted to a hospital between August 2015 and November 2016 were followed: 4883 (50\%) patients participated.

Main outcome measures Primary outcome was health status, measured with the EuroQol-5-dimensions-3-levels $(E Q-5 D)$, including a cognition item and the EuroQol Visual Analogue Scale. Health status was collected at 1 week, 1 , $3,6,12$ and 24 months after injury. Potential prognostic factors were based on literature and clinical experience (eg, age, sex, pre-injury frailty (Groningen Frailty Index), pre-injury EQ-5D).

Results Health status increased mainly during the first 6 months after injury with a mean EQ-5D utility score at 1 week of 0.49 and 0.79 at 24 months. The dimensions mobility, pain/discomfort and usual activities improved up to 2 years after injury. Lower pre-injury health status, frailty and longer length of stay at the hospital were important prognostic factors for poor recovery. Spine injury, lower and upper extremity injury showed to be prognostic factors for problems after injury. Traumatic brain injury was a prognostic factor for cognitive problems. Conclusion This study contributes to the increase in knowledge of health recovery after injury. It could be a starting point to develop prediction models for specific injury classifications and implementation of personalised medicine.

Trial registration number NCT02508675.

\section{INTRODUCTION}

Trauma, defined as a physical injury, is one of the leading causes of disability and affects millions of people worldwide each year. The number of survivors after trauma has increased over several decades, due to the improvement of trauma care. ${ }^{1-3}$ However, many patients suffer physical, psychological or cognitive impairments, resulting in a reduction of their health status.

The trauma population is a heterogeneous group of patients. Patients are from

\section{Strengths and limitations of this study}

A strength of the study was the short-term and longterm follow-up measurements to obtain essential recovery data of the injured patients.

- Another strength of the study is the high number of participants in this prospective cohort study.

- A limitation of this study is the possibility of selective drop-out, which could have resulted in an overestimation of reports after injury.

- Another limitation of this study is the possibility of selection bias, suggesting that more severely injured patients were more likely to participate.

various age groups with many different injury patterns, in both severity and body region. In addition, type of accident (eg, falls, road traffic accident) and mechanism of injury (eg, bleeding, fracture) can be diverse. The identification of patients at high risk of poor health status would enable clinicians to tailor treatment in which patients are referred to specialised care and rehabilitation at an early stage of their recovery or to lifelong treatment or lifestyle changes.

Previous research identified several prognostic factors for poor outcome after injury, for example, age, gender, educational level, comorbidity and pre-injury work status. ${ }^{4-16}$ Most previous studies on prognostic factors for health status evaluated major or severe trauma patients population, ${ }^{4-9}{ }^{12-15}$ patients with traumatic brain injury (TBI $)^{514}$ or a small follow-up trauma population. ${ }^{11}$ In addition, one study focused on long-term follow-up measurement, 2-7years after injury. ${ }^{8}$ Last, pre-injury health status was not assessed as prognostic factor for health status in previous studies. Although recovery after injury is not only determined by injury severity or injury in specific body regions, research that takes into account the total clinical trauma population during their recovery is scarce. ${ }^{16}$ In addition, different recovery patterns can be expected 


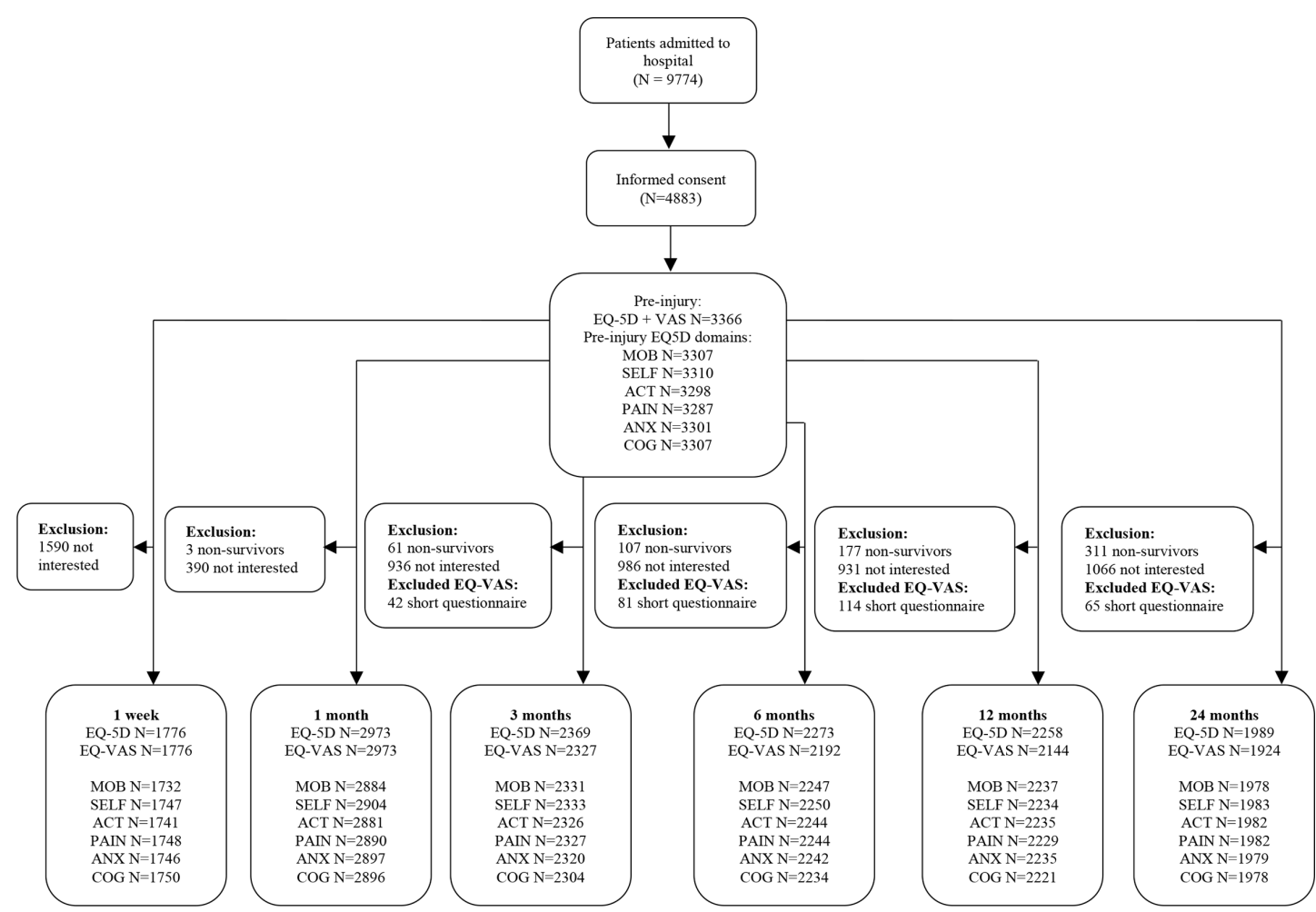

Figure 1 Flow diagram of study participation. Non-survivors are participants who died during the follow-up period. ACT, usual activities; ANX, anxiety/depression; COG, cognition; EQ-5D, EuroQol-5-dimensions-3-levels; EQ-VAS, EuroQol Visual Analogue Scale; MOB, mobility; N, number; PAIN, pain/discomfort; SELF, self-care.

in, for example, patients with brain injury and patients suffering from lower/upper extremity injury.

This study aimed to determine prognostic factors for health status and determine recovery patterns of health status after injury in the clinical trauma population and in specific injury classifications.

\section{METHODS}

\section{Study design and participants}

Data were obtained from the Brabant Injury Outcome Surveillance (BIOS). The BIOS Study is a prospective observational cohort study in which health status, costs, functional and psychological outcomes were assessed in the first 24 months after injury. A detailed description of the methods of the BIOS Study can be found in the published research protocol. ${ }^{17}$

All adult ( $\geq 18$ years) patients admitted to a hospital in the region North Brabant (the Netherlands) from 1 August 2015 to 30 November 2016 due to an injury and who survived to hospital discharge were included in this study. Patients without sufficient knowledge of the Dutch language or with pathological fractures (eg, osteoporosis) were excluded. A proxy informant (caregiver or family member) was asked to complete the selfadministered questionnaires if patients were incapable of completing the questionnaires in the BIOS Study from 1 month onwards. Proxy informant use of the EuroQol-5dimensions-3-levels (EQ-5D-3L) was validated previously in an injury cohort. ${ }^{18}$ The questionnaires were sent by post or electronically at 1 week, 1 month, 3 months, 6 months, 12 months and 24 months after injury. All participants, patients or proxy informants, signed informed consent. If patients did not complete the corresponding BIOS questionnaire, they were asked to complete a shorter version of the questionnaire at 3 months, 6 months, 12 months and 24 months after injury to increase the response rate. This short version incorporates only a small collection of the questionnaires that are included in the BIOS Study (eg, EQ-5D, demographics and return to work). Patients who did not respond to a questionnaire were considered a non-participant for that time point, but could participate again in the following questionnaires. Patients were called to inform them about the BIOS Study and were asked for reasons of non-participating. Non-responders were patients who did not complete informed consent nor complete a follow-up questionnaire. Injury characteristics were collected in the Brabant Trauma Registry and were merged to the BIOS data for all participating patients.

\section{Patient and public involvement}

No patients were involved.

\section{Outcome}

Health status was measured with the EQ-5D-3L (EQ-5D) ${ }^{19}$ This questionnaire consists of the EQ-5D descriptive system and the EuroQol Visual Analogue Scale (EQ-VAS). The EQ-5D descriptive system comprised the following five dimensions: mobility, self-care, usual activities, pain/ 
Table 1 Patient characteristics; table of participants and non-responders of the BIOS Study

\begin{tabular}{|c|c|c|c|}
\hline & Participants* & Non-responders & $P$ value \\
\hline $\mathrm{N}(\%)$ & 4883 & 4891 & \\
\hline Male (\%) & $2329(48)$ & $2407(49)$ & 0.13 \\
\hline Age (median, IQR) & $68(53-80)$ & $70(46-84)$ & 0.26 \\
\hline 18-24 years $(\mathrm{N}, \%)$ & $217(4)$ & $400(8)$ & \\
\hline 25-44 years $(\mathrm{N}, \%)$ & $516(11)$ & 767 (16) & \\
\hline 45-64 years (N, \%) & $1364(28)$ & $1006(21)$ & \\
\hline $65-74$ years $(N, \%)$ & $963(20)$ & $563(12)$ & \\
\hline$\geq 75$ years $(\mathrm{N}, \%)$ & $1823(37)$ & $2155(44)$ & \\
\hline \multicolumn{4}{|l|}{ ASA classification $(\mathrm{N}, \%)$} \\
\hline 1 (healthy) & $1531(31)$ & $1195(24)$ & 0.00 \\
\hline 2 & $2348(48)$ & $1657(34)$ & \\
\hline 3 & $950(19)$ & $1046(21)$ & \\
\hline 4 (severe systemic disease) & $54(1)$ & $40(1)$ & \\
\hline Missing & - & $953(20)$ & \\
\hline Injury Severity Score (median, IQR) & $5(4-9)$ & $5(2-9)$ & 0.00 \\
\hline Length of stay at hospital (median, IQR) & $4(2-8)$ & $4(2-8)$ & 0.02 \\
\hline $1-2$ days $(\mathrm{N}, \%)$ & $1444(30)$ & $1528(31)$ & \\
\hline $3-7$ days $(\mathrm{N}, \%)$ & $2081(43)$ & $1642(34)$ & \\
\hline $8-14$ days $(\mathrm{N}, \%)$ & $995(20)$ & $911(19)$ & \\
\hline$\geq 15$ days $(\mathrm{N}, \%)$ & $363(7)$ & $421(9)$ & \\
\hline Missing & - & $389(8)$ & \\
\hline Functional Capacity Index (N, \%) & & & 0.00 \\
\hline $1-2$ (worse state) & $248(5)$ & $169(4)$ & \\
\hline $3-4$ & $2074(42)$ & $1721(35)$ & \\
\hline 5 (best possible state) & $2561(52)$ & $2473(51)$ & \\
\hline Missing & - & $528(11)$ & \\
\hline \multicolumn{4}{|l|}{ Injury classification (N, \%) } \\
\hline Pelvic injury & $293(6)$ & $151(3)$ & \\
\hline Hip fracture & $1266(26)$ & $1099(23)$ & \\
\hline Tibia, complex foot or femur fracture & $569(12)$ & $505(10)$ & \\
\hline Shoulder and upper arm injury & $473(10)$ & $417(9)$ & \\
\hline Radius, ulna or hand fracture & $308(6)$ & $283(6)$ & \\
\hline Head injury with AIS <2 & $1324(27)$ & $1443(30)$ & \\
\hline Head injury with AIS >3 & $186(4)$ & $181(4)$ & \\
\hline Facial injury & $249(5)$ & $303(6)$ & \\
\hline Thoracic injury & $198(4)$ & $162(3)$ & \\
\hline Rib fracture & $451(11)$ & $398(8)$ & \\
\hline Mild abdominal injury & $87(2)$ & $89(2)$ & \\
\hline Severe abdominal injury & $36(1)$ & $30(1)$ & \\
\hline Spinal cord injury & $27(1)$ & $10(0)$ & \\
\hline Stable vertebral fracture or disc injury & $301(6)$ & $249(5)$ & \\
\hline Admission to intensive care unit (N, \%) & $358(7)$ & $292(6)$ & 0.00 \\
\hline \multicolumn{4}{|l|}{ Educational level (N, \%)† } \\
\hline Low & $2670(55)$ & - & \\
\hline Middle & $1305(27)$ & - & \\
\hline
\end{tabular}




\begin{tabular}{|c|c|c|c|}
\hline & Participants* & Non-responders & $P$ value \\
\hline High & 908 (19) & - & \\
\hline Pre-injury work status $†$ & $1278(38)$ & - & \\
\hline Pre-injury frailty† & $762(16)$ & & \\
\hline \multicolumn{4}{|l|}{ Pre-injury health status $\dagger$} \\
\hline EQ-5D utility (mean, SD) & $0.85(0.23)$ & - & \\
\hline EQ-VAS (mean, SD) & $79.4(18.2)$ & - & \\
\hline$\%$ problems mobility & $1051(32)$ & - & \\
\hline$\%$ problems self-care & $530(16)$ & - & \\
\hline$\%$ problems usual activities & $856(26)$ & - & \\
\hline$\%$ problems pain/discomfort & $1044(32)$ & - & \\
\hline$\%$ problems anxiety/depression & $540(16)$ & - & \\
\hline$\%$ problems cognition & 651 (19) & - & \\
\hline Missing & $1517(31)$ & & \\
\hline
\end{tabular}

*Patients who completed at least one follow-up questionnaire. Missing variables were imputed. †Variables were only collected in responders.

AIS, Abbreviated Injury Scale; ASA, American Society of Anaesthesiologists; EQ-5D, EuroQol-5-dimensions-3-levels; EQ-VAS, EuroQol Visual Analogue Scale; N, number.

discomfort and anxiety/depression. Each dimension could be answered in three levels: no problems, some problems and severe/extreme problems.

A summary score of the EQ-5D (ie, EQ-5D utility score) can be calculated by using the Dutch tariffs. ${ }^{20}$ The EQ-5D utility score ranged from 0 (death) to 1 (perfect health). The EQ-VAS is a vertical VAS with 0 indicating the worst imaginable health state and 100 indicating the best imaginable health state.

Cognition was added as an additional dimension to the EQ-5D questionnaire. Respondents were asked to describe their or, in case of proxy, the patients' state of health, concerning cognition (eg, memory, concentration). Similar to the other dimensions, answer options were based on three levels: no problems, some problems and severe problems.

Health status was measured at each time point during follow-up in both patient and proxy questionnaires. The EQ-5D (including the cognition dimension) and EQ-VAS were also measured pre-injury, by asking participants at 1 week or 1 month and proxy informants at 1 month for the patients' health status before sustaining the injury. The EQ-5D with cognition dimension and EQ-VAS were both included in the BIOS Study. The short questionnaire only included the EQ-5D and cognition dimension.

\section{Prognostic factors}

Prognostic factors can be subdivided into sociodemographic variables and clinical variables and were chosen based on previous literature and clinical experience. ${ }^{4-16}$

\section{Sociodemographic variables}

Possible prognostic factors for health status that were measured in the BIOS Study were sex, age, educational level (low, middle or high), pre-injury work status (yes/ no), frailty and pre-injury health status. Educational level was categorised in three levels as the highest completed degree, diploma of education: low (primary education, preparatory secondary vocational education or without diploma), middle (university preparatory education, senior general secondary education or senior secondary vocational education and training), and high (academic degree or university of applied science). Frailty was measured at 1 week or 1 month after injury with the Groningen Frailty Index in patients $\geq 65$ years. ${ }^{21} \mathrm{~A}$ sum-score of $\geq 4$ was considered frail.

\section{Clinical variables}

Possible clinical prognostic factors for health status were length of hospital stay, Injury Severity Score (ranging from 1: mild injury to 75: fatal injury), admission to the intensive care (yes/no), presence of comorbidities and the Functional Capacity Index. Comorbidities were measured with the American Society of Anaesthesiologists (ASA) physical status classification system ranging from 1 (healthy patient) to 4 (severe systemic disease that is a constant threat to life). The Functional Capacity Index and Injury Severity Score were based on the Abbreviated Injury Scale (AIS) codes (AIS-90, update 2008). ${ }^{22}$ All clinical variables were extracted from the trauma registry.

\section{Injury classification}

The AIS codes (AIS-90, update 2008) ${ }^{22}$ were used to create injury group classifications representing the most common types of injuries. In total, 14 injury groups were created: 3 lower extremity injury groups (pelvic injury, hip fracture, and tibia fracture/complex foot fracture 
or distal/shaft femur fracture), 2 upper extremity injury groups (shoulder and upper arm injury, and radius, ulna or hand fracture), 2 TBI groups (AIS-head $\leq 2$ and AIShead $\geq 3$ ), 1 face injury group, 2 thorax injury groups (thorax injury and rib fracture), 2 abdomen injury groups (AIS-abdomen $\leq 2$ and AIS-abdomen $\geq 3$ ) and 2 spine injury groups (spinal cord injury/brachial plexus lesion and stable vertebral fracture/disc injury) (online supplemental file 1). Patients who suffer multiple injuries could be classified in one or more injury group classifications.

\section{Data analysis}

Baseline characteristics of participants were compared with characteristics of non-responders, using $\mathrm{X}^{2}$ for categorical variables or the Mann-Whitney $\mathrm{U}$ test for nonnormal distributed data. Normality was checked visually with a normal $\mathrm{Q}-\mathrm{Q}$ plot. Descriptive statistics included the median with the IQR, mean with SD for continuous variables and number with percentage for categorical variables. Missing baseline characteristics $(0.9 \%$ for the Injury Severity Score and $6.8 \%$ for length of stay at hospital) and missing EQ-5D utility scores for participants (ranging from $1.8 \%$ at 1-week follow-up to $6.9 \%$ at 12-month follow-up) were imputed according to multiple imputation by using the multivariate imputations by chained equations procedure with 15 imputations and 5 iterations. ${ }^{23}$ The imputation model included baseline characteristics, injury characteristics and summary scores of the follow-up questionnaires to capture associations with missingness as completely as possible. Detailed description of the imputation model and imputed values were previously published. ${ }^{24}$ No large differences were found between imputed data analyses and complete case analyses.

Multicollinearity was checked based on the variance inflation factor (criterion: >10). Prognostic factors were assessed for poor health status outcome with EQ-5D utility scores and EQ-VAS as outcome measures. Regression coefficients with corresponding 95\% CI were reported. The dimensions of the EQ-5D descriptive system were dichotomised into $0=$ no problems and $1=$ some problems/extreme problems. Logistic mixed models with random intercepts were used to assess prognostic factors for poor outcome for the six dimensions of the EQ-5D (eg, mobility, self-care, usual activities, pain/discomfort, anxiety/depression and cognition). All potential prognostic factors were included in the multivariable regression models to calculate adjusted ORs and corresponding 95\% CI. Age and length of stay at the hospital were included as categorical variables, because of the nonlinear relation between factor and outcome.

Recovery patterns of health status were determined by changing the reference category of the categorical time variable in linear mixed models for health status and logistic mixed models for the dimensions of health status, adjusted for the prognostic factors. Recovery patterns for the items of the EQ-5D were assessed in detail for injury classifications that showed to be statistically significant for the dimensions in the total multivariable model.

Analyses were conducted in the statistical programs $\mathrm{R}$ V.3.4.0 (R Foundation for Statistical Computing, Vienna, Austria) and IBM SPSS V.24, and results were reported according to the Transparent Reporting of a multivariable prediction model for Individual Prognosis or Diagnosis guidelines. ${ }^{25} \mathrm{~A}$ p value of $\leq 0.05$ was considered statistically significant.

\section{RESULTS}

\section{Baseline characteristics}

A total of 4883 patients ( $50 \%$ of total, $\mathrm{N}=9774$ ) completed at least one questionnaire of the BIOS Study of whom $48 \%$ $(\mathrm{N}=2329)$ were men (figure 1 , table 1 ). The median age was 68 years with an IQR of 53-80 years. Participants had a median Injury Severity Score of 5 (IQR 4-9) and most of the patients were classified as healthy or as patients with mild systemic disease $(\mathrm{N}=3879,79 \%)$. A total of 358 patients $(7 \%)$ were admitted to the intensive care unit. The majority of the participants had low educational level $(\mathrm{N}=2670,55 \%)$ and $38 \%$ of the participants $(\mathrm{N}=1278)$ had a job prior to injury. Mean pre-injury EQ-5D utility score (SD) was $0.85(0.23)$. A total of 762 participants (27\% of participants $\geq 65$ years) reported to be frail.

Compared with the non-responders, participants were more severely injured, were more often admitted to the intensive care unit (7\% vs 6\%), had lower Functional Capacity Index values and were more often healthy (measured with the ASA classification).

A total of 1105 participants (22.6\% of the study population) completed all BIOS questionnaires at each time point. The main reason for not participating was that completing the questionnaire was too time consuming. Patients who reported to be fully recovered and patients aged 18-24 years were most likely to be lost to follow-up.

\section{EQ-5D over time}

The mean EQ-5D utility (SD) scores were 0.49 (0.32), $0.56(0.30), 0.69(0.27), 0.76(0.25), 0.77(0.26)$ and $0.79(0.25)$ at 1 week, 1, 3, 6, 12 and 24 months, respectively (figure 2A, online supplemental file 2). The mean EQ-VAS (SD) scores were 58.26 (20.45), 63.02 (20.46), 69.48 (18.56), 72.97 (17.28), 73.50 (18.08) and 75.58 (17.88) at 1 week, 1, 3, 6, 12 and 24 months, respectively. Patients reported the most increase in EQ-5D utility scores during the first 6 months, with a little improvement up to 12 months.

The first month, patients reported most problems for the following dimensions of the EQ-5D: pain/discomfort, usual activities, mobility and self-care (figure 2B,C, online supplemental file 2). During the 24-month follow-up, the percentages of patients reporting problems for pain/ discomfort, usual activities and mobility were highest. Two years after injury $49 \%$ (95\% CI: $47 \%$ to $51 \%$ ) of the patients reported problems for pain/discomfort, $43 \%$ (95\% CI: $41 \%$ to $45 \%$ ) reported problems for mobility, 
A

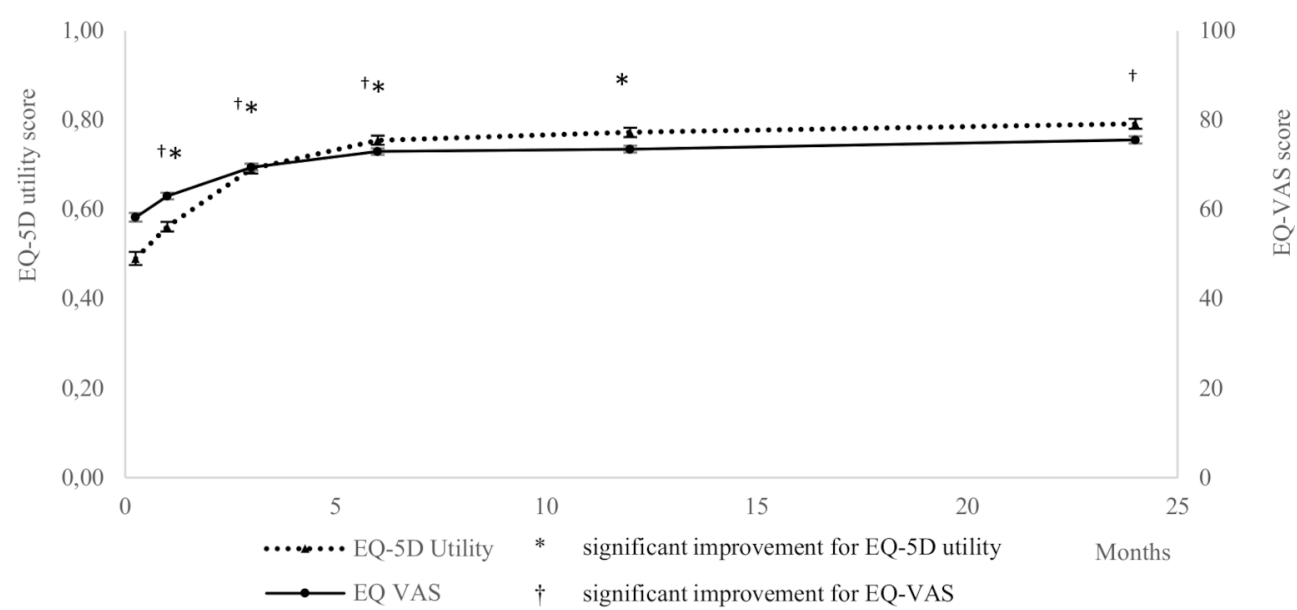

B

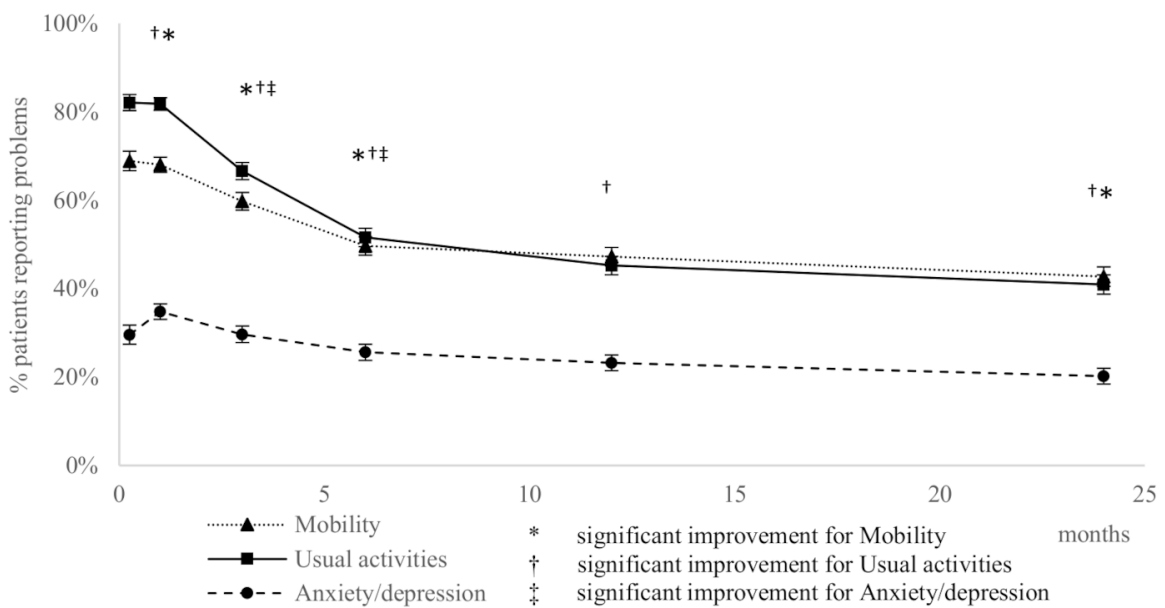

C

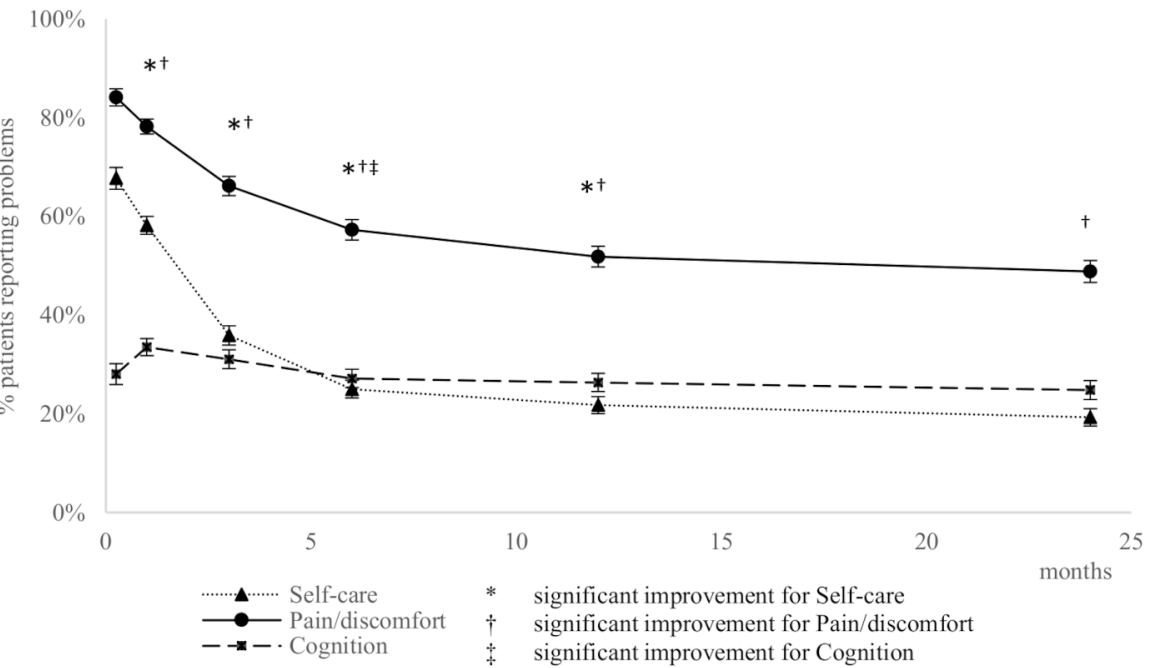

Figure 2 (A) Health status scores $(95 \% \mathrm{Cl})$ and $(\mathrm{B}, \mathrm{C})$ percentage of patients reporting problems $(95 \% \mathrm{Cl})$ on the dimensions of the EQ-5D-3L, including whether there was a significant change in health status scores compared with the previous time point. EQ-5D-3L, EuroQol-5-dimensions-3-levels; EQ-VAS, EuroQol Visual Analogue Scale.

$41 \%$ (95\% CI: $39 \%$ to $43 \%$ ) reported problems for usual activities, $25 \%$ (95\% CI: $23 \%$ to $27 \%$ ) reported problems for cognition, $20 \%$ (95\% CI: $18 \%$ to $22 \%$ ) reported problems for anxiety/depression and 19\% (95\% CI: $17 \%$ to $21 \%$ ) for self-care.

\section{Prognostic factors}

Almost all variables were prognostic factors for an increase of the EQ-5D utility score in the univariate analyses (online supplemental file 3). Lower pre-injury health status, frailty and longer length of stay at hospital were important significant prognostic factors for decreased EQ-5D utility score, decreased EQ-VAS and its dimensions 
during the first 2 years after injury in the multivariable analyses (table 2). Age is a prognostic factor for self-care, usual activities, pain/discomfort, anxiety/depression and cognition, but no significant association was found for mobility. Sex showed to be a significant prognostic factor for all outcomes, except for mobility and self-care.

Lower extremity injury (pelvic injury, hip fracture and tibia, complex foot or femur fracture) was a prognostic factor for the EQ-5D utility score, mobility, self-care, usual activities and pain discomfort. Upper extremity injury (shoulder and upper arm injury, radius, ulna or hand fracture) was a prognostic factor for the EQ-5D utility score, mobility and self-care. Spine injury (spinal cord injury or stable vertebral fracture or disc injury) was a prognostic factor, although not always significant, for health status, and the dimensions mobility, self-care, usual activities and pain/discomfort. TBI was a prognostic factor for problems with cognition.

\section{Recovery patterns for injury classifications}

Recovery for dimensions of health status among different injury classifications mostly occurred up until 12 months after injury, except for pain/discomfort (table 3). Patients with lower extremity injury reported significant less problems at 24 months compared with 12 months for pain/ discomfort.

Patients with spine injury showed improved mobility up to 6 months for mobility and self-care, and up to 12 months for pain/discomfort and usual activities. Upper and lower extremity injury showed the same recovery pattern during the first 2 years for self-care, with significant improvement up to 12 months after injury.

\section{DISCUSSION}

In this multicentre prospective cohort study, we found that patients reported problems up until 2 years after injury. Health status was especially low during the first 6 months after injury, in which patients often reported problems in most of the dimensions of health status. Lower pre-injury health status, frailty and longer length of stay at hospital were prognostic factors for both decreased health status during the first 2 years after injury. For the EQ-5D dimensions mobility, usual activities and pain/discomfort less problems were reported at 2 years compared with 1 year after injury, as for the other dimensions we found no decrease in reported problems after 1 year.

The prevalence of problems in the dimensions of health status decreased during 2-year follow-up. Although a recent study in severely injured patients demonstrated higher prevalence of problems in the health status dimensions, ${ }^{6}$ our results are in line with another study in the general clinical trauma population. ${ }^{16}$

Previous research showed that age is a prognostic factor for reduced health status. ${ }^{9} 1626$ In contrast, results from this study showed improved overall health status. This could be explained by the addition of the strong prognostic factors pre-injury health status and frailty in the multivariable adjusted models, indicating that not the increase of age is a prognostic factor for poor health status, but the patients' health status before injury. Not all elderly patients are frail nor are they in poor health. With the ageing population, frailty and pre-injury health status are essential to consider when assessing recovery patterns in injured patients. We found that increasing age was a prognostic factor for less problems with usual activities, pain/discomfort, anxiety/depression and cognition. This is also in contrast with a recent study, stating that the relationship between age and the dimensions of EQ-5D differed. ${ }^{6}$ Again, the different findings can be attributed to the additional strong predictors. This is confirmed by the univariate analyses which demonstrate that increasing age is associated with more problems on all dimensions of health status, except anxiety/depression and cognition.

The addition of the cognitive dimension on the EQ-5D has previously been shown to improve classification and validity, especially in patients with $\mathrm{TBI}^{27}{ }^{28} \mathrm{In}$ line with these findings, this study showed that patients with TBI were at risk of developing cognitive problems after injury. It has been suggested previously that most patients with mild TBI recover fully within 3-6 months, although some patients with mild TBI and patients with more severe TBI suffer persistent cognitive problems. ${ }^{29-31}$ Our study showed that patients with TBI reported no further improvement in health status after 6 months, in line with the recovery pattern of patients with mild TBI. This is possibly due to the fact that most participants of the BIOS Study suffered mild TBI (27\%) compared with moderate/severe TBI (4\%). Further evaluation of these subgroups with more specific outcome measures is necessary to determine their recovery patterns.

In line with previous studies, this study showed that female sex is a prognostic factor for poor health status after injury. ${ }^{46} 13-1632$ It has been suggested that problems were more often reported in women, in contrast to men, who dismiss their problems more often. Another explanation could be that women experience more psychological impact, resulting in lower health status.

Except for longer length of stay at the hospital, no injuryrelated characteristics were found to be prognostic factors for anxiety/depression reports. These results suggest that psychological problems after injury are mainly based on patient characteristics, which is confirmed in previous research. 334

Although the large prospective longitudinal design of this study is a major strength, there are also some limitations. First, only $50 \%$ of the patients responded to the BIOS Study. We found differences in injury and patient characteristics between participants and non-responders of the BIOS Study, for example, participants were more severely injured compared with the non-responders, indicating selection bias. Next, it is also possible that selective drop-out has occurred. We suspect that patients who were fully recovered were less likely to respond to the follow-up questions, resulting in an overestimation of reports after injury. In addition, retrospectively collected pre-injury 


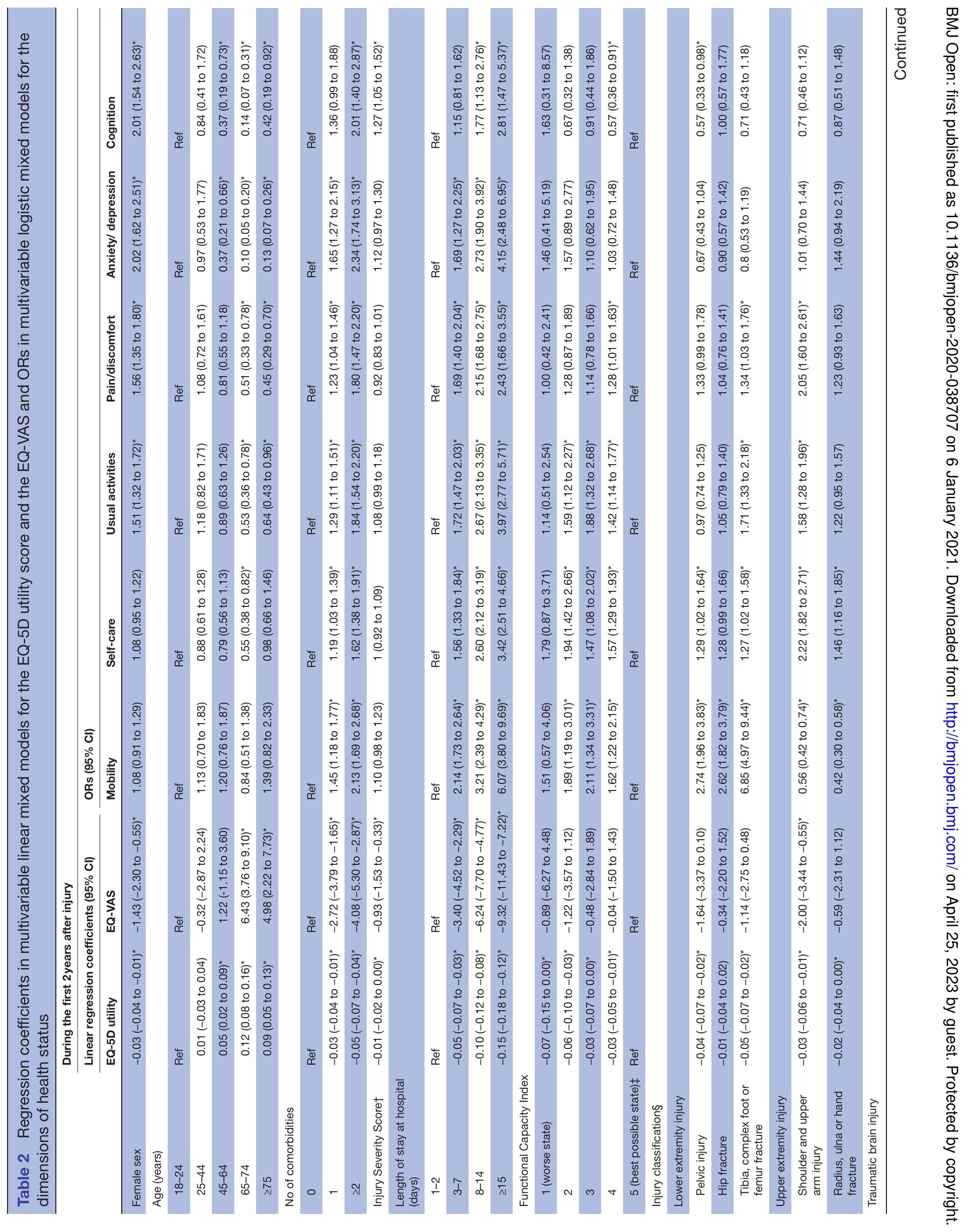




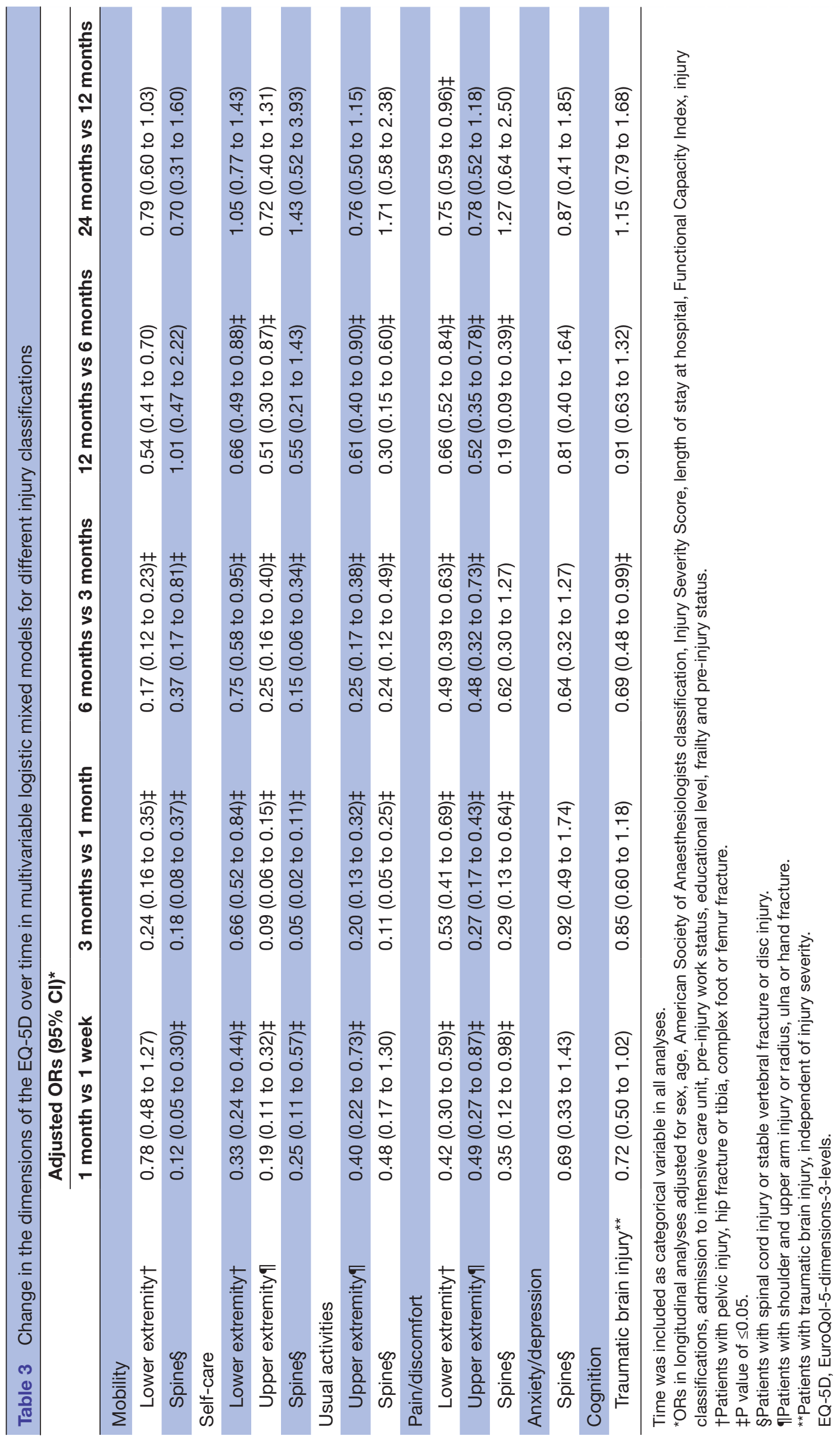


health status scores are prone to recall bias and response shift. ${ }^{35}$ However, they are considered more appropriate compared with general population norm scores. ${ }^{36}$ Last, frailty was only assessed in patients aged $\geq 65$ years. This could have introduced bias, because younger patients may be frail. However, we believe this would only affect a small proportion in this large cohort.

Next, generalisability of the study results can be questioned, because inclusion criteria for injured patients could be different from other registries. This study included all injury severities and elderly patients with hip fracture.

We acknowledge that long-term non-fatal outcomes should be incorporated in the trauma registry. ${ }^{37}$ These outcomes could be used to inform caregivers and patients about their expected recovery patterns. However, preinjury health status is essential in predicting short-term and long-term outcome after injury and should therefore also be included in the registry. Furthermore, the dimensions of the EQ-5D and health status showed to have different recovery patterns for different injury classifications. Non-fatal outcome should not only be focused on health status, but especially on the different dimensions.

Knowledge about individual recovery patterns can induce specific interventions to increase health status and improve recovery after injury. For example, previous research demonstrated a need to identify patients who may be experiencing mental health issues for timely referral and appropriate care after injury. ${ }^{38}$ In addition, the prediction models can contribute to realistic expectations of their recovery for injured patients. ${ }^{38} 39$

Although the responding patients demonstrated recovery after 6 months for the dimensions anxiety/ depression and cognition, the dimensions mobility, pain/ discomfort and usual activities still improved up to 2 years after injury. These results contribute to the increase in knowledge of recovery patterns of health status after injury and could be a starting point to develop prediction models for specific injury classifications and implementation of personalised medicine.

Contributors LdM, SP and MACdJ contributed to conception and design of this study. LdM and MACdJ contributed to data collection. LdM, SP, RJMH, EWS and MACdJ contributed to analyses and interpretation. LdM, SP, RJMH, EWS and MACdJ contributed to preparation of the manuscript. The final version of the article was approved by all the authors.

Funding This work was supported by a grant of the Dutch organisation for health research and care innovation (ZonMW) section TopCare projects (grant number: 80-84200-98-14226).

Competing interests None declared.

Patient consent for publication Not required.

Ethics approval The study was approved by the Medical Ethics Committee Brabant (project number BIOS Study: NL50258.028.14 and short questionnaire: NW2016-09).

Provenance and peer review Not commissioned; externally peer reviewed.

Data availability statement Data are available upon reasonable request. Data from this study can contain potentially identifying or sensitive patient information. Data are anonymised, but due to relatively few severe cases, patients could be identified. Therefore, data from the BIOS Study will be made available for researchers who provide a methodologically sound proposal. Requests may be sent to secretariaat@nazb.nl.

Supplemental material This content has been supplied by the author(s). It has not been vetted by BMJ Publishing Group Limited (BMJ) and may not have been peer-reviewed. Any opinions or recommendations discussed are solely those of the author(s) and are not endorsed by BMJ. BMJ disclaims all liability and responsibility arising from any reliance placed on the content. Where the content includes any translated material, BMJ does not warrant the accuracy and reliability of the translations (including but not limited to local regulations, clinical guidelines, terminology, drug names and drug dosages), and is not responsible for any error and/or omissions arising from translation and adaptation or otherwise.

Open access This is an open access article distributed in accordance with the Creative Commons Attribution Non Commercial (CC BY-NC 4.0) license, which permits others to distribute, remix, adapt, build upon this work non-commercially, and license their derivative works on different terms, provided the original work is properly cited, appropriate credit is given, any changes made indicated, and the use is non-commercial. See: http://creativecommons.org/licenses/by-nc/4.0/.

ORCID iD

Leonie de Munter http://orcid.org/0000-0001-6573-2032

\section{REFERENCES}

1 Liberman M, Mulder DS, Lavoie A, et al. Implementation of a trauma care system: evolution through evaluation. J Trauma 2004;56:1330-5.

2 Cameron PA, Gabbe BJ, Cooper DJ, et al. A statewide system of trauma care in Victoria: effect on patient survival. Med $\mathrm{J}$ Aust 2008;189:546-50.

3 Moore L, Hanley JA, Turgeon AF, et al. Evaluation of the long-term trend in mortality from injury in a mature inclusive trauma system. World J Surg 2010;34:2069-75.

4 Christensen MC, Banner C, Lefering R, et al. Quality of life after severe trauma: results from the global trauma trial with recombinant factor VII. J Trauma 2011;70:1524-31.

5 Andelic N, Hammergren N, Bautz-Holter E, et al. Functional outcome and health-related quality of life 10 years after moderate-to-severe traumatic brain injury. Acta Neurol Scand 2009;120:16-23.

6 Gabbe BJ, Simpson PM, Cameron PA, et al. Long-Term health status and trajectories of seriously injured patients: a population-based longitudinal study. PLoS Med 2017;14:e1002322.

7 Sluys K, Häggmark T, Iselius L. Outcome and quality of life 5 years after major trauma. $J$ Trauma 2005;59:223-32.

8 Ulvik A, Kvåle R, Wentzel-Larsen T, et al. Quality of life 2-7 years after major trauma. Acta Anaesthesiol Scand 2008;52:195-201.

9 Holtslag HR, van Beeck EF, Lindeman E, et al. Determinants of long-term functional consequences after major trauma. J Trauma 2007;62:919-27.

10 Aitken LM, Davey TM, Ambrose J, et al. Health outcomes of adults 3 months after injury. Injury 2007;38:19-26.

11 Sampalis JS, Liberman M, Davis L, et al. Functional status and quality of life in survivors of injury treated at tertiary trauma centers: what are we neglecting? J Trauma 2006;60:806-13.

12 Harris I, Dao ATT, Young J, et al. Factors predicting patient satisfaction following major trauma. Injury 2007;38:1102-8.

13 Ringburg AN, Polinder S, van lerland MCP, et al. Prevalence and prognostic factors of disability after major trauma. $J$ Trauma 2011;70:916-22.

14 Steel J, Youssef M, Pfeifer R, et al. Health-Related quality of life in patients with multiple injuries and traumatic brain injury $10+$ years postinjury. J Trauma 2010;69:523-31.

15 Holbrook TL, Hoyt DB. The impact of major trauma: quality-oflife outcomes are worse in women than in men, independent of mechanism and injury severity. J Trauma 2004;56:284-90.

16 Polinder S, van Beeck EF, Essink-Bot ML, et al. Functional outcome at 2.5, 5, 9, and 24 months after injury in the Netherlands. $J$ Trauma 2007;62:133-41.

17 de Jongh MAC, Kruithof N, Gosens T, et al. Prevalence, recovery patterns and predictors of quality of life and costs after non-fatal injury: the Brabant injury outcome surveillance (bios) study. Inj Prev 2017;23:59-62.

18 Gabbe BJ, Lyons RA, Sutherland AM, et al. Level of agreement between patient and proxy responses to the EQ-5D health questionnaire 12 months after injury. J Trauma Acute Care Surg 2012;72:1102-5.

19 EuroQol Group. EuroQol--a new facility for the measurement of health-related quality of life. Health Policy 1990;16:199-208. 
20 Lamers LM, McDonnell J, Stalmeier PFM, et al. The Dutch tariff: results and arguments for an effective design for national EQ-5D valuation studies. Health Econ 2006;15:1121-32.

21 Steverink N, Slaets J, Schuurmans H. Measuring frailty: developing and testing the GFI (Groningen frailty indicator). Gerontologist2001;41:236-7.

22 Gennarelli TA, Wodzin E. Abbreviated injury scale 2005: update 2008. Russ Reeder, 2008.

23 van Buuren S, Oudshoorn K. Flexible multivariate imputation by MICE. PG/VGZ/99.054, 1999.

24 Kruithof N, Polinder S, de Munter L, et al. Health status and psychological outcomes after trauma: a prospective multicenter cohort study. PLoS One 2020;15:e0231649.

25 Moons KG, Altman DG, Reitsma JB. Transparent reporting of a multivariable prediction model for individual prognosis or diagnosis (TRIPOD): explanation and ElaborationThe TRIPOD statement: explanation and elaboration. Ann Intern Med 2015;162:W1-73.

26 Gabbe BJ, Simpson PM, Harrison JE, et al. Return to work and functional outcomes after major trauma. Ann Surg 2016;263:623-32.

27 Geraerds AJLM, Bonsel GJ, Janssen MF, et al. The added value of the EQ-5D with a cognition dimension in injury patients with and without traumatic brain injury. Qual Life Res 2019;28:1931-9.

28 Ophuis RH, Janssen MF, Bonsel GJ, et al. Health-Related quality of life in injury patients: the added value of extending the EQ-5D-3L with a cognitive dimension. Qual Life Res 2019;28:1941-9.

29 Frencham KAR, Fox AM, Maybery MT. Neuropsychological studies of mild traumatic brain injury: a meta-analytic review of research since 1995. J Clin Exp Neuropsychol 2005;27:334-51.
30 Carroll L, Cassidy JD, Peloso P, et al. Prognosis for mild traumatic brain injury: results of the who collaborating centre Task force on mild traumatic brain injury. J Rehabil Med 2004;36:84-105.

31 Rabinowitz AR, Levin HS. Cognitive sequelae of traumatic brain injury. Psychiatr Clin North Am 2014;37:1-11.

32 Bazarian JJ, Blyth B, Mookerjee S, et al. Sex differences in outcome after mild traumatic brain injury. J Neurotrauma 2010;27:527-39.

33 Quale AJ, Schanke A-K, Frøslie KF, et al. Severity of injury does not have any impact on posttraumatic stress symptoms in severely injured patients. Injury 2009;40:498-505.

34 Wiseman TA, Curtis K, Lam M, et al. Incidence of depression, anxiety and stress following traumatic injury: a longitudinal study. Scand $J$ Trauma Resusc Emerg Med 2015;23:29.

35 Scholten AC, Haagsma JA, Steyerberg EW, et al. Assessment of preinjury health-related quality of life: a systematic review. Popul Health Metr 2017;15:10.

36 Watson WL, Ozanne-Smith J, Richardson J. Retrospective baseline measurement of self-reported health status and health-related quality of life versus population norms in the evaluation of post-injury losses. Inj Prev 2007;13:45-50.

37 Haider AH, Herrera-Escobar JP, Al Rafai SS. Factors associated with long-term outcomes after injury: results of the functional outcomes and recovery after trauma emergencies (forte) multicenter cohort study. Ann Surg 2018;271:1165-73.

38 Sleney J, Christie N, Earthy S, et al. Improving recovery-Learning from patients' experiences after injury: a qualitative study. Injury 2014;45:312-9.

39 Mancuso CA, Sculco TP, Salvati EA. Patients with poor preoperative functional status have high expectations of total hip arthroplasty. $J$ Arthroplasty 2003;18:872-8. 